\section{Step by step zum ePaper}

Schritt 1: Wenn Sie bei SpringerMedizin.de noch keinen Account haben, müssen Sie sich zunächst unter www.springermedizin. de/register anmelden und als Arzt ausweisen - Laien bleibt der Zugriff verwehrt. Wenn Sie schon einen Zugang haben, loggen Sie sich bitte ein und gehen direkt zu Schritt 2.

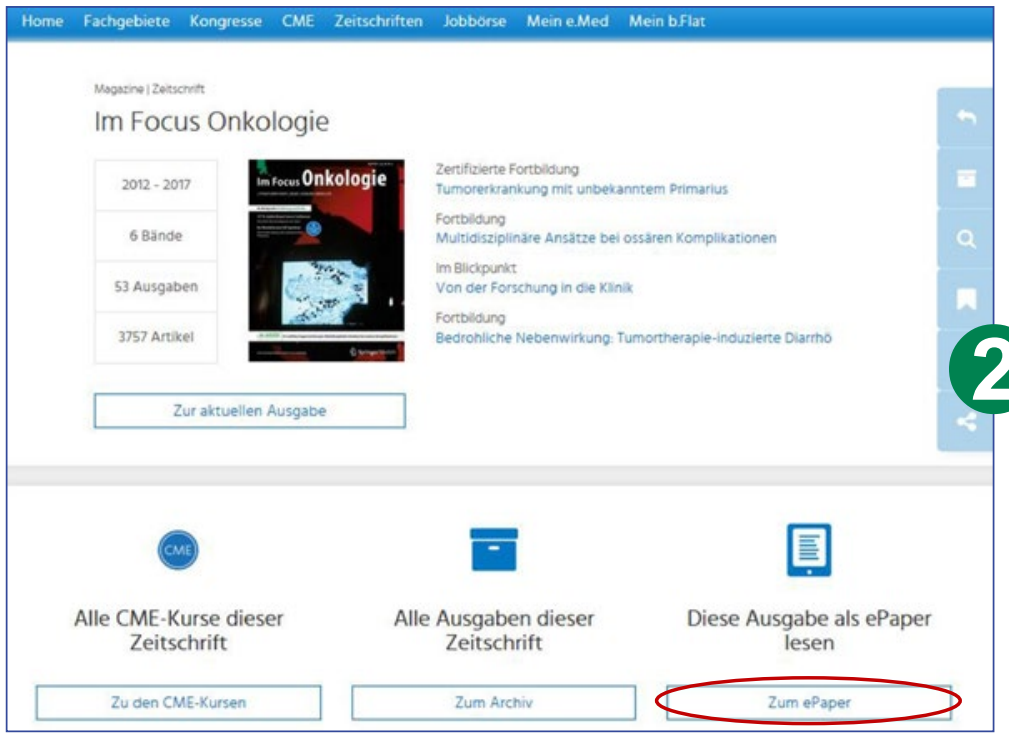

Schritt 3: Das ePaper öffnet sich in einem neuen Fenster. Über die Pfeiltasten oder durch Ziehen mit der Maus blättern Sie durch die Ausgabe. Mit einem Doppelklick auf den gewünschten Text wird dieser herangezoomt. Suchen Sie einen bestimmten Beitrag im Heft, können Sie in der Suchmaske Schlagwörter eingeben oder durch Klicken im interaktiven Inhaltsverzeichnis sofort auf der richtigen Seite landen. Eine Übersicht aller Seiten bietet der Button „Thumbnails“.

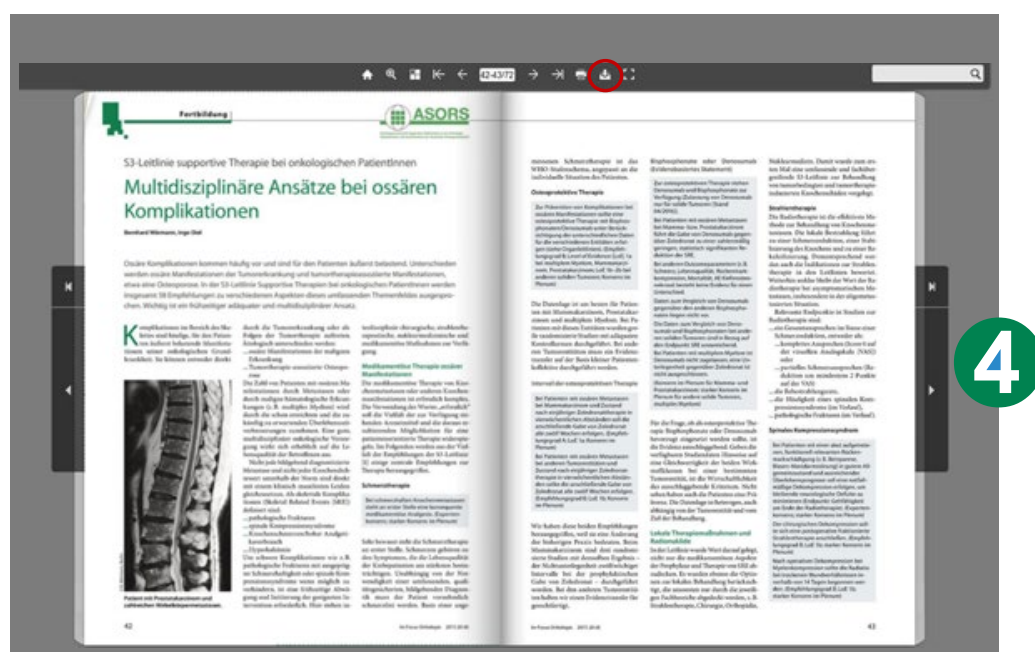

Springer Medizin

a *

Home Fachgebiete Praxis und Bent Kongresse CME MeineMed Zeischniten Jobbosse
Registrierung

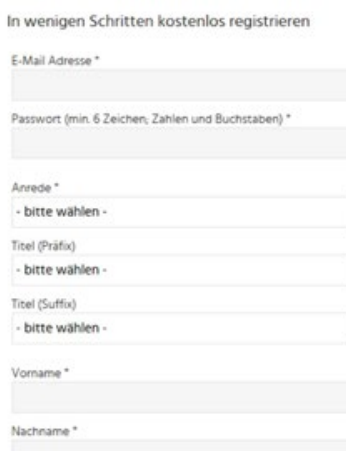

Schritt 2: Navigieren Sie zur Startseite von Im Focus Onkologie unter www.springermedizin.de/im-focus-onkologie. Dort erscheint die aktuelle Ausgabe der Zeitschrift. Unten rechts finden Sie den Button „Zum ePaper“. Auf dieser Seite können Sie außerdem im Archiv nach älteren Heften suchen oder direkt zum CME-Modul der Ausgabe wechseln.

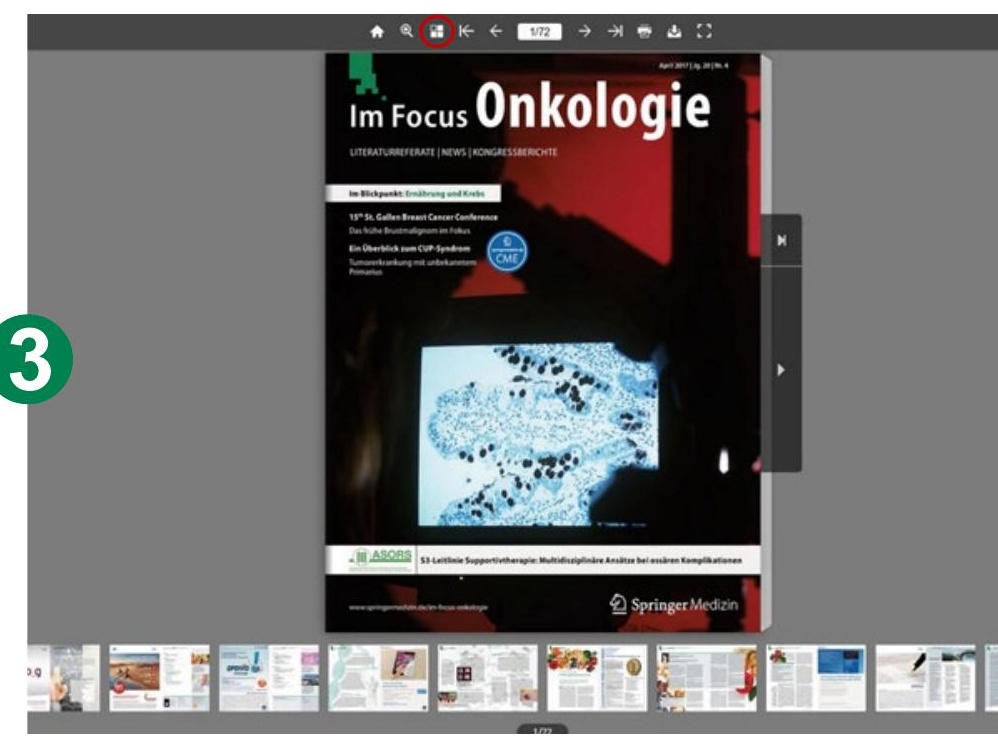

Schritt 4: Auch unterwegs im Urlaub oder im Flugzeug ohne Internetverbindung lässt sich „Im Focus Onkologie“ auf dem Tablet durchblättern: Laden Sie dazu das ePaper über das Symbol „Download“ in der Navigationsleiste oben direkt auf Ihr Gerät. Damit haben Sie eine oder auch mehrere Ausgaben Ihrer Zeitschrift jederzeit offline abrufbar. Julia Rustemeier 